\title{
Psychiatry in Jamaica
}

\section{Frederick W. Hickling DM MRCPsych(UK) DFAPA}

Professor of Psychiatry, Department of Community Health and Psychiatry, University of the West Indies, Mona, Kingston 7, Jamaica email frederick.hickling@uwimona.edu.jm

\begin{abstract}
The intense historical relationship linking Jamaica and Britain to 300 years of the transatlantic slave trade and 200 years of colonialism has left 2.7 million souls living in Jamaica, $80 \%$ of African origin, 15\% of mixed Creole background and $5 \%$ of Asian Indian, Chinese and European ancestry. With a per capita gross domestic product of US $\$ 4104$ in 2007, one-third of the population is impoverished, the majority struggling for economic survival. The prevailing religion is Protestant, although the presence of African retentions such as Obeah and Pocomania are still widely and profoundly experienced, and the powerful Rastafarian movement emerged as a countercultural religious force after 1930 . The paradox and contradictions of five centuries of Jamaican resistance to slavery and colonial oppression have spawned a tiny, resilient, creative, multicultural island people, who have achieved a worldwide philosophical, political and religious impact, phenomenal sporting prowess, astonishing musical and performing creativity, and a criminal underworld that has stunned by its propensity for violence.
\end{abstract}

\section{Policy and service}

Hickling \& Sorel (2005) discuss mental health policy and legislation in Jamaica and the English-speaking Caribbean, and the development of the Lunatic Asylum in Kingston.

Mental health legislation originated from colonial Britain in 1872, cementing the draconian policy of police arrest for lunacy and incarceration in the oppressive lunatic asylums that has dogged the history of mental healthcare in the UK, with successive attempts at legislative reform in that country in the 20th century. Jamaica broke with this British tradition in 1974 by virtually abandoning the custodial approach to the treatment of mental illness, and by the creation of a nationwide system of care that marginalised police involvement in the management of people with a mental illness, and placed their treatment squarely in the purview of the medical and nursing professions. As a result, a community mental health system has now evolved that is situated firmly in the primary healthcare system of the country, with seminal links to public sector medical and nursing professionals.

A network of over 300 clinics in the island of 4400 square miles provides a full range of mental health services, delivered primarily by community mental health nurses (called mental health officers), supervised by 30 psychiatrists. More than 40000 patients are treated annually. Treatment is provided free of charge, with the full range of internationally available psychotropic medications and psychiatric treatments. The community mental health service provides a mobile community follow-up service that keeps track of the hundreds of patients who have problems with medication adherence, and provides emergency services, crisis intervention and acute hospitalisation when necessary.

More than $60 \%$ of those patients requiring hospital admission for acute mental illness are admitted to the medical wards of the 13 general hospitals island-wide (Hickling et al, 2000). The generally trained medical and nursing practitioners who work in these hospitals provide care for those admitted for psychiatric treatment, side by side with those with diabetes and heart disease, under the supervision of the community psychiatrist and mental health officers assigned to those hospitals. A Cochrane review (Hickling et al, 2007) found that this remarkable therapeutic reality is unique to Jamaica.

The remaining $40 \%$ or so of patients requiring hospital admission are admitted to specialised psychiatric units in three major hospitals serving the two major urban centres of Kingston and Montego Bay. The average length of hospital stay for acutely ill patients is about 14 days. The Mental Health Law of 1997 provides the legal statute that allows patients to be admitted and detained involuntarily for up to 14 days. The majority of all admissions are voluntary, and no facility outside of prison exists where a patient can be detained involuntarily for a longer period. Community treatment orders and legal sections that can determine the involuntary incarceration of a patient for up to 6 months at a time, as exist in countries such as England, do not exist under Jamaica's mental health legislation.

After 37 years of measured deinstitutionalisation, the Bellevue Mental Hospital is now a 700-bed institution with 100 acute beds serving a catchment area of 90000 persons in the city of Kingston, with custodial facilities for more than 600 indigent patients over the age of 65 .

Although the island's mental health service accounts for $5 \%$ of the health budget, which in turn is $6.5 \%$ of the national budget, vibrant private treatment facilities in psychology and psychiatry now exist island-wide.

\section{Training}

The Jamaican mental health success story is due in no small measure to the effect of the medical, psychiatric and nursing training at the University of the West Indies (UWI), Mona. The UWI, which was established in 1948 as a school of the 
University of London, has trained nearly 6000 medical practitioners since its inception. In addition, its School of Nursing (UWISON) has provided the undergraduate and postgraduate training for many thousands of nurses in Jamaica. Psychiatric training was introduced for all nurses and medical students in 1965, thus providing a comprehensive primary and secondary medical care programme provisioned by 3000 medical and 5000 nursing practitioners, which buttresses the psychiatric service in the island. Psychiatric residents and medical students receive apprenticeship and academic tutoring in the 20-bed open ward unit run on therapeutic community principles at the University Hospital of the West Indies. The accident and emergency department and the in- and outpatient services of the University Hospital reinforce the broad, eclectic secondary care training experience, with practical primary care training being provided in the government-run community mental health services.

Recent postgraduate training programmes for clinical psychologists (Hickling \& Matthies, 2004) now provide the basis for the development of psychological assessment and psychotherapy services.

A robust child and adolescent service has emerged around the country in tandem with the adult mental health services, and the UWI is now implementing a training programme in child and adolescent psychiatry to provide the specialists to further develop these services. Similar training programmes in substance misuse and forensic psychiatry are being developed at the UWI. UWISON also conducts a robust nurse practitioner and mental health officer training programme.

\section{Specialist services and research}

In 2005, the UWI launched the Caribbean Institute of Mental Health and Substance Abuse (CARIMENSA) for delivering primary prevention in mental health across the country and the region. Aimed at developing programmes to reduce national problems such as violence, substance misuse, teenage pregnancy, HIV/AIDS and other chronic diseases, this Institute, situated in the Faculty of Medical Sciences, has developed a novel cultural therapy programme (Hickling, 2004), which incorporates innovative ethnographic group methods with creative arts therapies for risk reduction for people of all ages, classes and ethnicities. A 3-year 'Dream-a-World' cultural therapy pilot programme (Hickling, 2006) was initiated with a cohort of 9-year-old inner-city primary school children who were exhibiting behavioural and academic problems. The preliminary results of this programme indicated significantly higher scores on the government grade- 6 achievement test for the study group compared with a control group, as well as a reduction in behavioural problems, more significantly in boys. In 2008, CARIMENSA implemented a novel MSc in cultural therapy at the UWI, to train cultural therapists in primary prevention processes for the nation.

The UWI has had a seminal influence on mental health research in Jamaica. The institutional public policy at the beginning of the new millennium of appointing Caribbean psychiatrists with a high-output research record to lead mental health at the university certainly paid dividends in terms of mental health research output (Hickling et al, 2008). This strategy has resulted in considerable increases in overall psychiatric research output (Gibson et al, 2007).
Collaboration with the Pan American Health Organization has highlighted Caribbean mental health research (Hickling, 2005) in the areas of epidemiology, public policy, treatment outcomes and service evaluation.

Recent quantitative (Gibson et al, 2008) and qualitative (Arthur et al, 2008) studies have demonstrated a profound reduction in stigma regarding mental illness in the island, related to a 'psychological deinstitutionalisation' process over the past 40 years, described by Whitley \& Hickling (2007). The establishment of the CARIMENSA Press in 2005 has triggered the launch of a Mental Health Observatory and the publication of five books on Caribbean psychology and psychiatry.

\section{Conclusion}

Detailed information on the mental health profile of Jamaica can be found in the World Health Organization's mental health atlas (2005) and in the book edited by Hickling \& Sorel (2005). The revolutionary transformation of the mental health landscape in Jamaica highlights the practical possibilities for efficient liberalisation of mental health practices worldwide, but especially in low- and middle-income countries. This transformation into an affordable, humane, modern and efficient system integrated into primary healthcare services, for all Jamaicans, is largely unrecognised at home and abroad and the comprehension of many people seems stuck at the image of the custodial 'snake pit' lunatic asylum that existed in the early 1960s. Old myths and legends are hard to eradicate, and no doubt this image will persist until the deinstitutionalisation process of the Bellevue Mental Hospital, started in 1972, is completed.

\section{References}

Arthur, C., Hickling, F. W., Gibson, R. C., et al (2008) The stigma of mental illness in Jamaica. In Perspectives in Caribbean Psychology (eds F. W. Hickling, B. K. Matthies, K. Morgan, et al). CARIMENSA Press.

Gibson, R. C., Morgan, K. A. D., Abel, W. D., et al (2007) Changing the research culture at the Section of Psychiatry, the University of the West Indies, Mona. West Indian Medical Journal, 56, 171-177.

Gibson, R. C., Abel, W. D., White, S., et al (2008) Internalizing stigma associated with mental illness: findings from a general population survey in Jamaica. Revista Panamericana de Salud Pública/Pan American Journal of Public Health, 23, 26-32.

Hickling, F. W. (2004) Popular theatre as psychotherapy. International Journal of Postcolonial Studies - Interventions, 6, 45-56.

Hickling, F. W. (2005) The epidemiology of common mental disorders in the English-speaking Caribbean. Pan American Journal of Public Health, 18, 256-261

Hickling, F. W. (ed.) (2006) Dream a World: CARIMENSA and the Development of Cultural Therapy in Jamaica. CARIMENSA Press.

Hickling, F. W. \& Matthies, B. (2004) The establishment of a clinical psychology postgraduate program at the University of the West Indies, Mona. Caribbean Journal of Education, 25, 25-36.

Hickling, F. W. \& Sorel, E. (eds) (2005) Images of Psychiatry - the Caribbean. Department of Community Health and Psychiatry, University of the West Indies Mona, and World Psychiatric Association.

Hickling, F. W., McCallum, M., Nooks, L., et al (2000) Treatment of first contact schizophrenia in open medical wards in Jamaica. Psychiatric Services, 51, 659-663.

Hickling, F. W., Abel, W., Garner, P., et al (2007) Open general medical wards versus specialist psychiatric units for acute psychoses. Cochrane Database of Systematic Reviews, issue 3, CD003290.

Hickling, F. W., Gibson, R. C. \& Abel, W. D. (2008) Public policy and mental health research at the University of the West Indies, 1995-2005. Journal of Education and Development in the Caribbean, 10, 87-96. 
Whitley, R. \& Hickling, F. W. (2007) Open papers, open minds? Media representations of psychiatric de-institutionalisation in Jamaica. Transcultural Psychiatry, 44, 659-671.
World Health Organization (2005) Jamaica. In Project Atlas: Resources for Mental Health, pp. 254-256. WHO. Available at http://www.who. int/mental_health/evidence/atlas/ (accessed October 2009).

\section{A decade of mental health services in Timor-Leste}

\section{Zoe Hawkins BM BCh MA}

Advisor to the Ministry of Health for Mental Health, Epilepsy and Health Research, Democratic Republic of Timor-Leste email zoe.hawkins@doctors.org.uk

\begin{abstract}
The Democratic Republic of Timor-Leste (East Timor) occupies the eastern half of the island of Timor, which lies north-west of Australia and within the eastern Indonesia archipelago. The population is approximately one million, of whom $45 \%$ are below the age of 15 . Average life expectancy is 59.5 years and $50 \%$ of the population live below the national poverty line of US $\$ 0.88$ per day. The official languages are Tetun and Portuguese, with Indonesian also used. The majority of the population are Catholic but also hold traditional animist beliefs.

Timor-Leste, a Portuguese colony for over 400 years, was invaded by Indonesia in 1975 following Portugal's rapid decolonisation. During the following 24 years of occupation, anti-insurgent and terror campaigns were carried out by the Indonesian military, with mass internal displacements of people and war-induced famines. Following a majority vote for independence in a 1999 referendum, a violent backlash from pro-Indonesia groups caused further deaths and mass destruction of buildings and infrastructure. Intervention by Australian-led peacekeeping forces restored stability, and the territory was administered by a United Nations mission until full independence was gained in 2002.
\end{abstract}

\section{History of mental health services}

During the years of Indonesian administration there were no mental health services in East Timor. In 1999, Psychosocial Recovery and Development in East Timor (PRADET) was founded by a partnership of mental health practitioners from Australia. Sixteen Timorese health workers underwent basic mental health training in Australia and returned to form the core staff of PRADET (Zwi \& Silove, 2002). In addition to providing assessment, diagnosis and treatment for people with mental illness, the staff of PRADET trained district health nurses in their follow-up care.

In 2002, the government established the East Timor National Mental Health Project (ETNMHP) as its mental health service, with technical support and training provided by a team of Australian mental health workers. PRADET continued as a local non-governmental organisation (NGO) to complement government services by providing psychosocial support, counselling and community education. In 2008, the ETNMHP became the Department of Mental Health within the Ministry of Health.

\section{Psychiatric morbidity}

An epidemiological study conducted in 2004 reported a point prevalence of psychosis (meeting DSM-IV criteria) of $1.35 \%$ and post-traumatic stress disorder of $1.47 \%$ (Silove et al, 2008). Since January 2008, the mental health service has seen a total of 3881 clients, of whom 1026 (26\%) have had a primary diagnosis of epilepsy. There are no data on the prevalence of different mental disorders within the remaining case-load. However, mental health workers report that psychotic disorders form the majority of cases, followed by depressive disorder.

\section{Mental health policy and legislation}

The government has a national mental health strategy (Ministry of Health Timor-Leste, 2005), which emphasises both a primary care approach to mental health services and partnerships with non-government service providers. There is currently no mental health legislation.

\section{Infrastructure}

The 260-bed National Hospital (Hospital Nacional Guido Valadares) is located in Dili, the capital, and provides secondary and tertiary healthcare services. There are also five regional referral hospitals in the districts. The National Hospital acts as the national referral centre and is the principal clinical training centre for health personnel studying in Timor-Leste. At present there is no mental health bed allocation and no psychiatric hospital.

Each of the 13 districts in Timor-Leste has a district health office, where clinical services for the area are coordinated and supervised. 